out damage; not to crack the spines, not to use library books for doorstops, coasters, umbrellas, or read them in the hot tub? For the most part, no one. Elementary and high school teachers don't do it any more. Librarians at the reference desk often are so harried they imitate the students' bad bookhabits. There are of course posters, bookmarks, handouts, etc., that can serve to educate usersbut how many administrators will go along with spending money for user education in preservation? Even if they see that it saves the library money in the long run, their decision-making often has to be aimed at the very short run, just to meet the exhausted budget.

So, troops, it's really up to those librarians who have the most contact with students, whether oneon-one or in a classroom situation; and that, folks, is us.

"But how can we talk about library preservation when we've only got 50 minutes to give a 90 minute lecture? It's unrealistic."

I know the feeling. But it doesn't have to take up a lot of time. A couple of slides or transparencies, a little commonsense talk, and the couching of this material in terms of informational benefit to the students themselves will give you the ability to make an impact in less than a minute. And if you're really pressed for time, handing out bookmarks with some basic information about the fragility of books and the importance of good handling practices will still have some impact. And if you still say you don't have time: how about prefacing your lecture with some remarks on disappearing information, while you wait for the stragglers to show up? $\mathrm{BI}$ people are creative and inventive by nature or necessity. You'll think up a way!

Ponder this: the next time a student presents a real need for guidance to you at the Reference Desk, and you think of a book you yourself used that helped you begin your way through the problem (say, Prefaces to Shakespeare) - well, will it still be there for your student to use? It really is worth the extra effort.

\title{
Self-instructed use of microcomputers in the library
}

\author{
By James R. Coleman
}

\author{
Assistant Director
}

Suffolk University

\author{
and Edmund G. Hamann
}

Director, Mildred F. Sawyer Library
Suffolk University
Librarians are embracing the microcomputer as eagerly as they did the photocopy machine three decades ago. From the initial "Apple in the corner," academic libraries have quickly expanded to microcomputer centers with extensive arrays of IBM or Apple compatible computers. The affinity of microcomputers with libraries is apparent: central location, long hours, access and control for software, and the service orientation of the staff. ${ }^{1}$ The first three attributes of libraries, location, hours and control, are generally taken for granted. Service orientation, however, is more often a presumption than a fact, given the librarians' relative inexperience with the new technology and the significant investment in staff time required. Recent articles in library literature stress the need for librarians to train and organize themselves to teach their clientele how to retrieve and manipulate information on microcomputers, just as they are expected to give instruction in retrieving and using print materials. The example of the popularity of

${ }^{1}$ Linda J. Piele, Judith Pryor, and Harold W. Tuckett, "Teaching Microcomputer Literacy: New Roles for Academic Libraries," College \& Research Libraries 47i(July 1986): 374. the microcomputer instructional program at Cornell's Mann Library supports this view. ${ }^{2}$

Although microcomputing facilities are available at Suffolk University to serve several divisions of the institution, restrictions on their use encouraged the Mildred F. Sawyer Library to establish a small microcomputer center of its own. The library offers free, unscheduled access to microcomputers (as well as dedicated wordprocessors) set up with software to perform a variety of tasks from wordprocessing to retrieving and manipulating commercial data files. However, it does not have sufficient staff to mount a supervised program of microcomputer instruction. Yet the library wished to be consistent with its excellent reputation as a "user-friendly" information service, a reputation reenforced by a vigorous program of bibliographic instruction. Therefore, at the time we installed microcomputers we were not prepared to ignore our service orientation and force users to fend for themselves.

${ }^{2}$ Linda Guyotte Stewart and James Markiewicz, "Teaching Information Retrieval: Lessons from Cornell," Wilson Library Bulletin 60) (March 1986): 32-32, 79 . 
Our solution was to use existing, inexpensive, menu-making software (and some modest amount of "hacking") to develop menu-driven, selfinstructing access to disk operating commands, applications programs, and data files. Our brand of instruction does not teach users how to use any particular software; for this the user must rely on tutorials, written manuals available in the library and the help screens of individual programs. But it does encourage the novice to get started and become comfortable enough with the machine to begin self-instruction. Since the microcomputers are located in the Reference area, a librarian on duty is available to re-boot machines accidentally turned off.

The microcomputers consist of five IBM PC clones, assembled and maintained by students in the university. Three of these are standard dual disk drive machines with $640 \mathrm{~K}$ of memory and two are single disk drives with $20 \mathrm{M}$ internal hard disks. Connected to them are three Hewlett-Packard “Thinkjet" and two Epson LX dot matrix printers. The menus and instructional screens are loaded to a "virtual disk" using $128 \mathrm{~K}$ of the machine's memory when the machines are booted. The machines are booted once a week and are on continuously. We have found that the machines are extremely stable for long periods of operation and need only to be installed with a program timer to prevent screen burn-in. We, therefore, ask students not to turn the machines off and on and, in fact, tape such a request over the power switch.

The instructional screens were written by Coleman using a screen formatter shareware program Screen Formatter. ${ }^{3}$ The menus were created using Automenu, originally a shareware program as well. ${ }^{4}$ The instructional screens are called from within the menus; thus the user is involved only in making choices from clear menu options. The main menu allows the user to select either introductory screens, screen descriptions of available software and data files, or (on the dual disk drive machines only) to void the screens entirely and use the machines as if there were no menus. The introductory screens are very elementary, explaining what to do, care of disks, where to get help, how to print, etc. The screens describing software are more substantive, including some description of commands within the selected software. Much in the fashion of the sophisticated commercial software, the menus instruct the user when he or she is to insert a particular disk in a specified drive.

Menu control is taken one step further in the hard disk machines. Drive A on these machines (the drive required to boot machines from disk) has been disabled as have the key combinations $\mathrm{Ctrl} / \mathrm{Alt} / \mathrm{Del}$ and Ctrl/C, internal commands to the

\footnotetext{
${ }^{3}$ Screen Formatter, Version 2.0. Indianapolis: Shamrock Microsystems.

${ }^{4}$ Automenu: Software Management System, Version 4.0. Norcross, Ga.: Magee Enterprises.
}

IBM PC which either reboot the machine or return to DOS. These key commands are disabled during the initial boot of the machine within CONFIG.SYS, at which time a "virtual" (RAM) disk is automatically created. An AUTOEXEC.BAT file then loads to the virtual disk the menus, instructional screens, and access menus to data files, tutorials and other software. When any user activity is ended, either through inactivity on the keyboard or quitting a program, the batch files created by Automenu return the machine to its virtual disk and its menus. Thus, the performance of hard disk machines is wholly "circular" and self-contained. Our obligations to software copyright are met, and the librarians are not constantly obligated to oversee the machines or to circulate "key" floppy disks.

This very low level of user interaction with the computer appears to be a successful, unsupervised way of encouraging the newcomer to get started. In the same vein, the library provides tutorial software, including tutorials on PC's, Lotus 1-2-3, and dBase III. These tutorials are promoted in the introductory screens as a good place for new users to start. The point is that the machines do not just sit there, awesomely grey and keyboard complex. Their screens invite the uninstructed user simply to press any or one particular key to move into and through a sequence of menus. At the same time, however, given the dual disk drive machines' menu option "Clear the machine for disk use," the screens do not stand in the way of experienced users wishing to proceed quickly beyond what they already know.

Applications programs and selected data files purchased by the library are either on the hard disk or available at the Reference Desk for the dual drive machines, or they may be the user's own copy. Thus, for example, a user may wordprocess a paper using a personal copy of Wordstar or a library registered copy of PC Write. One of the specific functions of the microcomputer service is to provide access to data sold to the library on floppy disks, such as Valuescreen (Valueline, Inc.), $C B D B$ (The Conference Board) and $B C D$, Business Conditions Digest, and eventually to data in the CDROM format or downloaded from remote databases.

Our experience is that this combination of machines, some in a "plain vanilla" configuration and others hard disk-based, and an instruction menu system, which may be skirted easily anytime users want to run their own software, is best for our library's purposes and capabilities. Among the users of the microcomputer center are many students enrolled in courses which give them access to the university's microcomputer laboratories, but who find the laboratories' limited hours inadequate. The arrangement is serving both our clients needs and our own desire to make popular proprietary software and various kinds of data accessible without supervision. 